\title{
Development of a Sourcebook Using Neuro-Linguistic Programming Technique in Teaching English as a Second Language
}

\author{
Rohaida Maunting-Derogongan \\ Mindanao State University, \\ Marawi City, Philippines
}

\author{
Gilbert Tamayao \\ Technological Institute of the Philippines, \\ Manila, Philippines
}

\begin{abstract}
This paper is an analysis of a sourcebook using Neuro-Linguistic Programming technique. The main objective is to determine the effectiveness of the sourcebook in teaching English as a second language. Specifically, it aimed to know the visual materials, aural presentations, and semi-abstract thoughts that would encourage the learners to actively participate in classroom discussions; the methods to be adapted; and the steps involved in the preparation of the sourcebook. It was found that most student-respondents strongly react to pictures, to feelings and sensations, and to ideas. The sourcebook must be prepared in the form of a content-based instructional material. It must include drills that would give ample approaches to develop among the learners good sense of collaborative learning, integrative global language proficiency, and contextual communicative competence in meaningful situations. Moreover, the sourcebook must use both print and non-print teaching aids as supporting materials.

Keywords: English language, English teaching, English sourcebook, NLP technique
\end{abstract}

\section{Introduction}

The use of traditional approach that dominates language teaching in the Philippines greatly hinders the development of English proficiency among learners. As a consequence, students learn about the language not the functional use. Most of the textbooks in English are conventional or grammatical in approach, which does not address the needs of the students for communicative competencies in the use of the English Language. Thus, students who could hardly listen, read, think, speak, and write English.

With all the problems interfering in the development of English proficiency, the question is how the language teacher remedies the situation in the classroom. This is a tremendous challenge posed to the language teacher of today. To respond to the challenge, a certain technique can be adapted in order to develop the proficiency in the English language.

Researches show that people try to improve information visually in pictures, aurally in sounds, kinetically in feelings based around the words. These models of communication are called Neuro-linguistic approaches. They are useful when considering how a learner reacts to the same stimulus. In other words, an emotional

Rohaida Maunting-Derogongan, Assistant Professor, Master of Arts in Education, English Department, Mindanao State University.

Gilbert Tamayao, Assistant Professor, Master of Arts in English, Humanities and Social Sciences Department, Technological Institute of the Philippines. 
appeal on the part of the student is being involved in the learning process. The cognitive stimulus is likewise catered for through an analysis of words, structures, discourse patterns, content, and interpretation. This technique utilizes modern approaches in language teaching such as the integrative, contextual, and communicative approaches.

These aforementioned approaches that are utilized in this technique can help solve the language problems of students. If this problem in the use of the language is solved, the refinement of the language learned comes next. Refinement will be done by undergoing some training in speaking by learning the correct pronunciation of the word, correct intonation of a sentence, and the English language as a second language of Filipinos.

\section{Statement of the Problem}

This study sought to know the development of a sourcebook using the Neuro-Linguistic Programming technique in teaching English as a second language at the Speech Laboratory.

Specifically, it aimed to answer the following questions:

What visual materials, aural presentations, and semi-abstract thoughts shall be included in the sourcebook that would encourage more learners to actively participate in classroom discussion?

What approaches or method shall be adapted in using these materials, presentation, and semi-abstract thoughts in teaching English as a second language?

What are the steps involved in the preparation of the sourcebook?

What are the strengths of the sourcebook?

\section{Assumptions}

Considering the foregoing conceptual framework, this study was based on the following assumptions.

(1) The Neuro-Linguistic Programming techniques develop among the learners good sense of collaborative learning, integrative global language proficiency, and contextual communicative competence in meaningful situations;

(2) The sourcebook is a content-based instructional material that is responsive to the needs in a particular milieu.

\section{Significance of the Study}

The researchers expected the following benefits which could be derived by different sectors from their paper:

(1) Curriculum planners can reassess the kinds of textbooks or materials to use for language teaching basically grammar focusing not only on the structure but also the proper way on how to pronounce words correctly with the correct accent and intonation pattern;

(2) Administrators will be motivated to plan and to implement regular or continuous in-service trainings among teachers on English proficiency;

(3) Professors will be encouraged to prepare their own instructional materials that respond to the needs and interests of their students;

(4) The students will be provided not only with interesting readings and pictures that sustain the motivation to participate fully in the classroom discussion but also with meaningful real-life communication situations that develop their proficiency of the language with ample listening, speaking, and writing skills; 
(5) Future researchers will further think and employ activities that would encourage students to express themselves in English with the correct American accent without sacrificing grammar.

\section{Scope and Limitations}

There are nine lessons namely the orientation and speech mechanism, vowels, diphthongs, consonant sounds, silent phonemes, schwa sounds, stress and the intonation of English and reduced sounds. Each lesson is good for one-hour duration per meeting only. Every lesson has the following features: objectives, subject matter, time frame, supporting materials, listening drills, and procedure.

The activities develop global language proficiency, social skills, and values that measure the intelligibility of students using English as a second language. The activities in the sourcebook were administered to the 726 freshmen students of Technological Institute of the Philippines who were enrolled in English $113 \mathrm{SL}$, first semester, school year 2007-2008.

\section{Definition of Terms}

The following terms are contextually defined as used in the study.

(1) American accent: A clearly distinguishable spoken language from the British accent that is adopted by Filipino English speakers;

(2) Audio materials: These are the recorded sounds to be played at the speech laboratory used as patterns in pronouncing words;

(3) Diction: A verbal description of words with regard to correctness and clearness in pronouncing words;

(4) Intonation: It is the matter of utterance following the rise and fall in the pitch of the voice in both spoken and written language;

(5) Language laboratory specialists: The professors who are in-charge of the enhancement training in English to be conducted at the Speech laboratory;

(6) Language proficiency: The ability of the learner to use the English language in both spoken and written language;

(7) Neuro-Linguistic Programming (NLP) technique: A technique to be used to be able to understand verbal and non-verbal materials interpreted by the brain that encourages learners to react on what they see and feel;

(8) Rudiments of grammar: These are the grammar rules to be learned to be able to construct sentences or statements correctly;

(9) Speech laboratory: The classroom that contains gadgets used to refine or enhance one's speaking ability. The learners are assigned to their respective cubicles;

(10) Sourcebook: This is a compilation of the activities to be undertaken during the course of study that includes drills and pictures.

\section{Related Literature}

Current views do not argue that skills are unimportant or that they should not be taught or assessed. However, recent curricular refocusing has moved from sub skills to the holistic processes of reading and writing, where the emphasis is on comprehending and composing larger pieces of text in a more global way. These global processes are viewed in communicative texts, and teaching as well as testing techniques 
emphasize the different purposes and functions of reading and pronouncing of words.

Nemah N. Hermosa (1991) in her journal, pointed out that with the view that skills instruction by itself lacks the intrinsic power to generate readers who read because reading is a valued part of their lives, there has been a perceptible shift from skills-based reading using basal reading program and workbooks to compilations of activities with emphasis on authentic thought-provoking pictures. Thus, learning and practice reading are placed in the context of good activities that nurture the joy and love for both reading and explaining.

Lilia Savovanglish and Richard Donato (1991), say that the problem for the language teacher is that majority of the textbooks provide few, if any, interactive activities in which students use the target language in collaborative tasks. Rather, commercially prepared materials like textbooks, workbooks, and the like generally equip the teacher with an array of form-focused exercises intended for teacher-fronted presentations. Even among the more communicative textbooks, group work is located at the end of a chapter after a series of mechanical exercises. Its position in the chapter subordinates group work to traditional exercise, creating the impression that mechanical exercises are necessary prerequisites to interaction in the target language. In this inferior position, group work activities are often perceived as unnecessary to the language-learning process or as optional activities to be used if class time permits. More attention should be given to interactive language-learning activity than is presently found in commercially prepared materials.

Perlita P. Romero and Pacelli S. Eugenio (1997) pointed out the Philosophy of Speech by saying that speech education rests upon a universal need - the need for one to exchange his ideas and feeling by verbal and non-verbal means, as well as with audible and visible means with other men. This need exists in all occupation, in all kinds of society and government, and at all ages raging from childhood to adulthood stage. They further stressed out that it starts on spoken message before it shall be written. The learner therefore must be equipped with the knowledge of communication and the communication process itself. To develop the listening skills according to them also plays a very important role. It is thought that one develops the skills in speaking by simply listening intently on the materials and then imitating how it is sounded. It is not therefore to shun the learner's fluency in speech and pronunciation.

Mildred B. Go et al. (1999), prove that foreign speakers of English today admit the more sensible goal in learning English is intelligibility. But what is intelligibility? It means being understood by a listener at a given time in a given situation. The aim is no longer to sound like a native speaker but to sound "close enough" so that the listener would easily get the message. In order to achieve this, stress and intonation must be taken into account.

Andrew M Colman presents that the Neuro-Linguistic Programming (NLP) is an approach to psychotherapy and a model of interpersonal communication, is borrowed from various disciplines which include the linguistics. Richard Bandler and the linguist, John Grinder, used the NLP as a method for personal development in the 1970s and its many variants are taught through seminars, workshops, books, and audio programs. The field is loosely spread and resistant to a single comprehensive definition. There is also a great deal of difference between the depth and breadth of training and standards. A basic method in NLP involves asking specific questions to help clarify the intended message in communication.

The NLP uses the pictorial representations where ideas featuring sound and touch involve the sensory modality that is involved in perception. NLP, this notion is extended to the performance of any task, such as making conversation, taking about a problem, reading a book, kicking a ball or riding a horse, representations consisting of images, sounds, feelings and smell and taste are constantly being formed and activated. 
The website ${ }^{1}$ presents this typical idea on NLP wherein it enhances all aspects of one's life by improving relationships with loved ones, learning to teach effectively gaining stronger sense of self-esteem, greater motivation, better understanding of communication, enhancing your business or career and an enormous amount of other things which involve the brain. It therefore gives opportunity to not only communicate better with others, but also to learn how to gain more control over what we considered to be automatic functions of our own neurology.

The proposed sourcebook adapts the key points of the aforementioned experts in teaching the English language in developing a meaty instructional material. It includes drills and activities that surely develop global language proficiency through collaborative learning activities.

\section{Conceptual Framework}

The study was based on the theory that people try to improve information visually in pictures, aurally in sounds, and kinetically in feelings based around the words. These models of communication are called Neuro-Linguistic approaches.

As the research paradigm illustrates, NLP will largely contribute to the development of a sourcebook as an aid in teaching English as a second language. They are useful when considering how a learner reacts to the same stimulus. In other words, an emotional appeal on the part of the student is being involved in the learning process. The cognitive stimulus is likewise catered for through an analysis of words, structures, discourse patterns, content, and interpretation. This technique utilizes modern approaches in language teaching such as the integrative, contextual, and communicative approaches.

The word "neuro" refers to nervous system when our experiences are received and processed through our five senses. The word "linguistic" pertains to our language both verbal and nonverbal. The word "programming" is used as a computer metaphor to explain our ability to discover and use the programs that we all mentally run. In other words, NLP is about how to use the technique of verbal and non-verbal communication to actively program our minds and to consistently achieve the results we want.

\section{Research Paradigm}

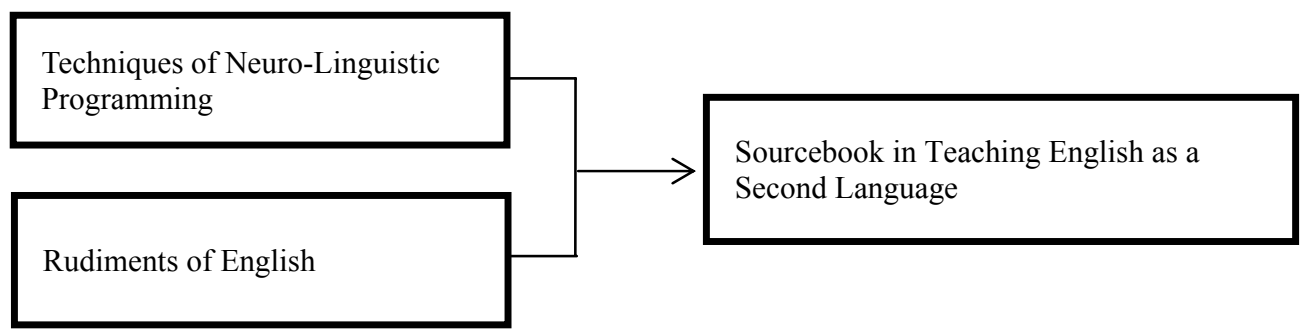

Figure 1. The development of the sourcebook in teaching English as second language.

\section{Methodology}

This study used the descriptive survey method of research to determine the effectiveness of the sourcebook in teaching English as a second language using the Neuro-Linguistic technique and the drills and approaches in the sourcebook.

\footnotetext{
${ }^{1}$ See www.nlpinfo.com.
} 
The respondents of this research were the 726 college freshmen students of Technological Institute of the Philippines who were enrolled in English 113 SL, first semester, school year 2007-2008.

A self-constructed springboard called sourcebook is used to conduct the different drills leading to the language proficiency of the student-respondents. The sourcebook is enriched by fusing chosen topics discretely designed for speech classes with audio-materials.

It contains the following topics: Orientation and Speech Mechanism, Vowels, Diphthongs, Consonant sounds, Silent phonemes, Schwa sounds, Stress and the Intonation of English and Reduced sounds. Each lesson is good for one-hour duration per meeting only. There are activities in every topic using words, sentences, symbols, songs, pictures, and tapes/CDs to develop among the learners good sense of collaborative learning. The conventional and contextual approaches of teaching are employed by the language specialists to measure the intelligibility of students using English as a second language.

To gather the data, an intensive administration of the simple lecture and different drills were done using the speech laboratory equipment where the student-respondents simply press the buttons of their response once they are asked about the sourcebook and the approaches employed by the professors.

The first draft was tried out to classes under the first batch to determine the clarity of directions, the equality of questions to be raised, the appropriacy of the activities, and the areas of difficulty if ever there are in the sourcebook. The findings of the tryout were the bases for the improvements or revisions made. The revised form was tried again to the second batch of the same section for further refinement of the sourcebook.

A simple frequency count and a percentage distribution were used to determine how the sourcebook works to the student-respondents.

\section{Results and Discussions}

Table 1

Materials to Be Included in the Sourcebook

\begin{tabular}{lll}
\hline Materials & Frequency & Percentage \\
\hline Words & 726 & 100.1 \\
Sentence & 430 & 59.22 \\
Symbols & 150 & 20.66 \\
Songs with accompaniment & 726 & 100.00 \\
Songs without accompaniment & 500 & 68.87 \\
Pictures & 726 & 100.00 \\
Tapes & 500 & 68.87 \\
\hline
\end{tabular}

Pictures, words, and songs are common preference of the materials that encourages more learners to actively participate in the classroom discussion with 726 or 100 percent of the student respondents. 500 or 68.87 percent preferred tapes; 430 or 59.22 percent preferred sentences; and 150 or 20.66 percent preferred symbols. Table 1 shows a common preference of the materials to be included in the sourcebook.

Table 2

Conventional Approach of Teaching

\begin{tabular}{lll}
\hline Approach & Frequency & Percentage \\
\hline Discrete point teaching or one skill at a time & 726 & 100.00 \\
Use of isolated sentences in lesson presentation and exercises in grammar & 620 & 85.39 \\
\hline
\end{tabular}




\begin{tabular}{lll}
\hline Use of pencil and paper type of evaluation & 123 & 16.94 \\
Teaching rudiments of grammar rather than content & 514 & 70.79 \\
Use of teacher-fronted activities & 100 & 13.77 \\
\hline
\end{tabular}

In Table 2, all the student respondents preferred a one skill at a time approach with a frequency of 726 or 100.00 percent of the total population. A frequency of 620 or 85.39 percent preferred the use of isolated sentences in lesson presentation; 514 or 70.79 percent preferred the teaching rudiments of grammar rather than content; 123 or 16.94 percent show their preference on the use of paper-pencil type of evaluation approach; and 100 or 13.77 percent preferred the use of teacher-fronted activities.

Table 3

Contextual Approach of Teaching

\begin{tabular}{lll}
\hline Approach & Frequency & Percentage \\
\hline Using songs with accompaniment & 726 & 100.00 \\
Using pictures & 726 & 100.00 \\
Using tapes & 701 & 96.55 \\
Getting meaning of unfamiliar words through context clues & 701 & 96.55 \\
Poem writing & 688 & 94.76 \\
\hline
\end{tabular}

Table 3 indicates that the students-respondents preferred the use of songs and the use of pictures in teaching as it garnered a 100.00 percent preference. A frequency of 701 or a 96.55 percent preferred the use of tapes and getting the meaning of unfamiliar words through context clues; 688 or 94.76 percent preferred the approach on poem writing;

Based on these findings, the sourcebook was prepared in the form of a content-based instructional material. It is further enhanced with drills that would give ample communicative approaches to develop among the learners good sense of collaborative learning, integrated global language proficiency and contextual communicative competence in meaningful situations. Moreover, the sourcebook uses both print and non-print teaching aids as supporting materials.

The findings on the assessment of the materials and approaches to be used in developing the sourcebook show that there is a great impact on the individual learner if the instructional material of the language laboratory teacher will respond to the need of the individual.

\section{Conclusion}

Based on the findings, the following conclusions were arrived at:

(1) Strong visual materials and various auditory skills bring about more positive results and strong logical reasoning;

(2) Much could be elicited from individual learners if language teaching is taught meaningfully through the use of real language situation and authentic materials;

(3) In as much as the teachers are educationally qualified to teach English, they have potential skills in producing teacher-made instructional materials for language teaching;

(4) The activities in the sourcebook can be used for the development of the communicative, contextual, and integrative approaches in language teaching. 


\section{Recommendations}

For the study to have utilitarian value, these are the recommendations:

(1) School administrators. Provision of a continuous faculty development program in the form of seminars and workshops that could update the teaching competencies of English professors on practical approaches to teaching;

(2) School administrators. Provision of in-service education to acquaint the teachers on the use of materials to be included in teaching;

(3) Curriculum Planners. Reassess the kind of textbooks to use for language teaching. The development of comprehension skills and communicative competence should be accorded of equal importance as grammatical analysis in teaching speech laboratory class;

(4) English professors. Develop a self-made sourcebook using various instructional aids which include visual materials, aural presentations, and semi-abstract thoughts in teaching the language;

(a) To develop the thinking, communicative and social skills, the materials in the sourcebook must provide songs and pictures that could be used in pair or group discussions where proper decorum in expressing ideas is observed;

(b) To train students to guess meanings of new words by context clues, the sentences, songs, and pictures must include hints that would discourage learners to be dictionary dependent;

(c) To develop in them important concepts and details of the materials, provide simple comprehension questions for students to answer;

(d) To serve its purpose, the materials prepared must be maximally used based on time allotted.

(5) Parallel studies should be undertaken on other English subjects.

\section{References}

Balisacan, T. F. (1987). Proposed instructional materials for the teaching of science VI Complete Elementary School, Rizal District. Philippines: Saint Paul University Philippines.

Colman, A. M. (2006). A dictionary of psychology. Oxford: Oxford University Press, Oxford Reference Online.

Concepcion, P. G., De La Cruz, E. M., \& Enriquez, L. P. (1994). Speech communication for Filipinos. Quezon City: Rex Book Store.

Dobson, J. M., \& Curry, D. (1994). Dialogues for everyday use (Office of Language Progress Division, United States of America).

Go, M. B., et al. (1999). Communication improvement for effective pronunciation. Philippines: Centro Escolar University.

Hermosa, N. N. (1991). Current perspective in reading education. The RAP Journal, XIV, 14-17.

Introduction to NLP. (2008). Retrieved from www.nlpinfo.com

Rogers, N. C., Fonacier, C. V., \& Bacon, W. (1972). Spoken English. Quezon City, Philippines: Alemen-Phoenix Publishing House, Inc.

Romero, P. P., \& Eugenio, P. S. (1997). Principles of speech and oral communication. Philippines: Katha Publishing Co., Inc.. Savovanglish, L., \& Donato, R. (1991). Group activities in the language classroom. English Teaching Forum, 22, 12.

Villanueva, P. C., Rellis, J. G., \& Cruz, E. E. (2000). Functional oral communication. Manila: University of Santo Tomas Publishing House. 